\title{
Slaying the Seven-Headed Dragon: The Quest for Gender Change in Academia
}

\author{
Marieke van den Brink and Yvonne Benschop*
}

In this article we propose a multi-level distinction between gender inequality practices and gender equality practices to come to better understanding of the slow pace of gender change in academia. Gender inequality resembles an unbeatable seven-headed dragon that has a multitude of faces in different social contexts. Based on an empirical study on the recruitment and selection of full professors in three academic fields in The Netherlands we discuss practices that should bring about gender equality and show how these interact with gender inequality practices. We argue that the multitude of gender inequality practices are ineffectively countered by gender equality practices because the latter lack teeth, especially in traditional masculine academic environments.

Keywords: change, gender practices, academic fields, recruitment and selection

\section{Introduction}

The underrepresentation of women in senior academic positions persists at an international level, 1 regardless of the variation in the history of higher education in different countries and regardless, too, of their varying equality policies (EU, 2008, 2009; Eveline, 2005; National Science Foundation, 2007; Osborn et al., 2000; Rees, 2002). Gender inequality resembles an unbeatable seven-headed dragon that has a multitude of faces in academic life. One of these 'heads' of gender inequality resulting in the underrepresentation of women is biased decision-making in academic appointments. This article focuses on the multiple gender practices in the recruitment and selection of full professors in The Netherlands. We examine the many gender inequality practices that are part of recruitment and selection in the ivory tower (Knights and Richards, 2003; Krefting, 2003; Van den Brink et al., 2010). We look at both these gender inequality practices and at measures that universities have taken to change the representation of women in the professoriate and analyse why these gender equality attempts have limited effects at best. The aim of this article is to come to a better understanding of how gender inequality practices in recruitment and selection affect gender equality practices to the point that sustainable change is impeded.

When it comes to achieving change, we argue that there is no such thing as academic practice in general. Academia is not a monolithic entity; gender practices do not always operate in the same way (Bourdieu, 1988; Kekäle, 1999; Musselin, 2002). In most studies on gender in academia, little distinction is made between academic fields. Academic fields vary in their core activities, financial resources, career patterns, epistemological issues and publishing strategies (Becher and Trowler, 2001; Cownie, 1998; Knorr Cetina, 1999). An important point of departure for this article is, therefore, the acknowledgement of differences in the academic field and the production of situated knowledge for different academic fields with regard to potential routes to gender change. We support scholars who argue that

Address for correspondence: *Radboud University Nijmegen, Institute for Management Research, PO Box 9108 , 6500 HK Nijmegen, e-mail: mcl.vandenbrink@fm.ru.nl 
various gender practices contribute to the emergence of gender inequality (Benschop and Doorewaard, 1998; Tienari et al., 2002) and contribute to our knowledge of the gender dynamics in specific academic contexts.

We begin by theorizing gender practices and propose a distinction between gender inequality and gender equality practices. In our view there is more to gender in organizations than the reproduction of gender inequality, and undoing gender inequality is the core target of change. After describing the cases and methodology, we outline the specific loss of women candidates in the appointment systems of the respective fields. We show that gender is not a static entity but is dynamically situated in various structural and cultural academic contexts. In these contexts, we subsequently examine the interaction of gender inequality and equality practices. We conclude with three explanations why it is often so difficult to undo gender in academia.

\section{Theorizing gender practices}

In line with what Lorber (2005) labels social construction feminism, we consider gender as an integral part of organizational practices (Acker, 1990; Benschop, 2001; Gherardi, 1994; Martin, 2006; Poggio, 2006). The 'practice turn' in gender studies has yielded revealing empirical and theoretical insight into the field of gender, work and organization (Poggio, 2006; Van den Brink and Stobbe, 2009). The conceptualization of gender as practice builds on the influential notion of 'doing gender' (West and Zimmerman, 1987). In her introduction of the special issue of Gender, Work \& Organization on gender as a social practice, Poggio outlines a theory of gender practices that sees gender as situated social practice, actualized through social interaction and rooted in the doing and saying of organizational actors, stating that

gender is constantly redefined and negotiated in the everyday practices through which individuals interact; how men and women 'do gender' and how they contribute to the construction of gender identities by engaging in a process of reciprocal positioning. (Poggio, 2006, p. 225)

The conceptualization of gender as a practice enables us to show the multiplicity, fluidity and situatedness of gender practices in various academic contexts. We argue that gender practices include both the practices that continuously reproduce gender inequalities and the practices that aim to bring about gender equality.

Of relevance here is the ongoing theoretical discussion in gender studies on doing and undoing gender. The undoing gender literature criticizes the notion of doing gender for its inevitable reproduction of gender inequality (Deutsch, 2007). Several authors propose a shift to undoing gender to emphasize the possibilities for change (Butler, 2004; Deutsch, 2007; Kelan, 2009; Lorber, 2005; Pullen and Knights, 2007). The central idea behind undoing gender is to accomplish gender change through social interactions and associated discourses that can reduce, dismantle, disrupt and challenge gender difference (Deutsch, 2007). However, there seems to be little consensus on what undoing gender exactly means and implies, how it is related to doing gender and how undoing gender leads to organizational change. This article contributes to the undoing gender debate by examining the relation between doing and undoing inequality. We argue that it is not so much gender per se that needs to be undone as it is the hierarchical power relation tied to it, at least when it comes to changing organizations. Thus, it is inequality that needs to become undone in order to foster change. What adds to the complexity here is that undoing and doing are always inextricably linked. Following Pullen and Knights (2007) who state that any undoing of gender is at one and the same time also a positive doing of some alternative, we contend that the undoing of gender inequality simultaneously entails a doing of something else. To come to better understanding of the ways to undo gender inequality we thus need to take into account how undoing inequality is related to multiple gender practices.

We therefore propose a multilevel distinction between gender inequality practices and gender equality practices to explain that there is more to gender in organizations than the perpetual reproduction of gender inequality and that undoing gender inequality is the core target of change. Our 
notion of gender inequality practices refers to the hierarchical distinction in which either women and femininity or men and masculinity are valued over the other. In the context of organizations this distinction predominantly amounts to powerful positions and privileges for men and masculinity. We use the notion of gender equality practices to refer to the policies and processes that aim to bring about gender equality. In other words, gender equality practices aim to undo gender inequality. The intentional gender policies and feminist intervention strategies that have been developed over the years (Ely and Meyerson, 2000; Kirton and Greene, 2005; Walby, 2005) fall under this category, as do organization processes that change unequal gender relations as an unintended effect. We will examine how gender equality and gender inequality practices intersect with, conflict with and anticipate each other. Both gender inequality practices and gender equality practices are manifold in today's universities and we demonstrate the myriad of manifestations of inequality and equality practices in the various academic fields. This way, we increase our understanding of the slow rate of change brought about by gender equality policies in higher education.

\section{Case and methodology}

\section{The Dutch case}

This article draws on empirical material constructed in a research project on recruitment and selection of full professors in The Netherlands (Van den Brink, 2010). International benchmarks repeatedly show that The Netherlands is at the back end of Europe when it comes to the percentage of women professors $(11 \%)$, even though Dutch women students outnumber and outperform men students (EU, 2009). Yet, there are remarkable differences between academic disciplines. In the humanities, medical sciences and natural sciences the percentage of women among professors is respectively 18.8, 12.9 and 7.7 per cent (Gerritsen et al., 2009).

The Dutch academic career system differs slightly from the Anglo-American one. Although we have translated Dutch ranks as if they corresponded directly with the US system (that is, assistant, associate and full professor), this is not in fact the case. There is no promotion system to progress from one rank to another. Traditionally, an upward career trajectory to the highest academic position in the Dutch system (full professor) depends not only on the individual merits of an academic but also on the positions available. Each step requires a vacant position and a recruitment and selection process. In that process, similar criteria to evaluate candidates are used as in the Anglo-American system; bibliometrics lead in assessing the work of academics, with an emphasis on international publications in top-tiered journals.

For this article we examined the various gender inequality and equality practices in each field. We selected three academic fields that include various disciplines. Although the distinction between fields is not unambiguous, each field has its own specific structure and logic (Maton, 2005, p. 689). Based on previous research, some differences between the recruitment and selection practices in academic fields were to be expected (Musselin, 2002). For instance, fields vary considerably with regard to the gender composition of students and staff, career patterns and the possibility of gaining additional funding. Three fields have been distinguished: humanities, natural sciences and medical sciences. We invited all 13 universities in The Netherlands to participate, but due to privacy issues and time scarcity of auxiliary personnel, only seven universities co-operated.

\section{Data collection}

This research study used qualitative and quantitative data collection methods. The quantitative data consisted of 971 committee reports covering almost all appointments of full professors at seven Dutch universities in the period 1999 to 2003. Information of the sex of men and women applicants - in general and on the shortlist - and of the final nominee, enabled us to reconstruct the academic pipeline. Qualitative data consisted of interviews with members of appointment committees. In total, 
Table 1: Selection of interview respondents and their gender

\begin{tabular}{|lll|}
\hline Subfields & Interview respondents & Gender \\
\hline Humanities & 13 committee members & $14 \mathrm{M}, 8 \mathrm{~F}$ \\
Natural sciences & 16 committee members & $14 \mathrm{M}, 5 \mathrm{~F}$ \\
Medical sciences & 21 committee members & $13 \mathrm{M}, 10 \mathrm{~F}$ \\
\hline
\end{tabular}

the first author interviewed 24 women and 40 men in the function of chairpersons (deans, vice-deans, directors of research and teaching managers). Some members of these appointment committees were also questioned in their role as former applicants. They reflected not only on their role and experiences in the committee but also on their experience during their own recent appointment procedure. All interviewees were full professors in their field.

The analytical focus of the interviews was on the recruitment and selection practices, that is to say, on what people say and do in their social interaction in organizations (Yanow, 2006). The interviewees were asked to describe the recruitment process and highlight the arguments used by committee members to explain their choice of the nominated candidate. We encouraged the respondents to talk about concrete yet anonymized cases and incidents, not about generalities. In an attempt to capture as much detail about the appointment process as possible, we asked the respondents to focus on the most recent appointment procedures they were involved in. Data were collected between October 2004 and January 2006.

\section{Data analysis}

To analyse the interviews we used qualitative content analysis (Lieblich et al., 1998). The content analysis was done by breaking the text into relatively small units of content on the basis of areas of interest. By giving open codes to different sections in the text, the first descriptive coding gave insight in the common patterns and themes of these research areas. We analysed the dominant patterns in each context that emerged from our data, producing three archetypical contexts that overlapped with the academic fields. Then we shifted to a more holistic content analysis, as researchers should interpret parts or categories of the text in light of the rest of the text (Ollerenshaw and Creswell, 2002). In this way, it became clear that some gender practices are dominant and more salient in specific fields. This is not to say that such gender practices were confined to certain fields but that they were most prominent in specific contexts. It is not the intention of this article to systemically compare the gender practices in the different fields. Rather, we are concerned with how gender equality and gender inequality practices in those fields intersect with, conflict with and anticipate each other. We used the computer software program Atlas-ti to systemize, code, compare and explore our data since this mapping method is appropriate for interpreting large numbers of interviews.

As feminist researchers working in academia ourselves we face some key ethical questions when conducting fieldwork and analysing the data. Fieldwork is a dialogical process, influenced by the positions and biographies of both researchers and the participants. The identity of the first author as a woman and $\mathrm{PhD}$ candidate played a role in the social interactions with the elite academics interviewed. Being 'just' a woman PhD candidate meant that she was relatively 'harmless' and this may have encouraged the disclosure of sensitive information that was contrary to the formal rules and regulations governing appointments. Many respondents were surprisingly frank, and some even boasted about moments when they had deviated from formal policies. Others paternalistically placed themselves in the role of $\mathrm{PhD}$ supervisor by interrupting and questioning the methodology and research questions of the project. Analysing the data as feminist researchers we run a risk of genderoversensitivity in interpreting the data (Alvesson and Billing, 2009). Our elaborate training in 


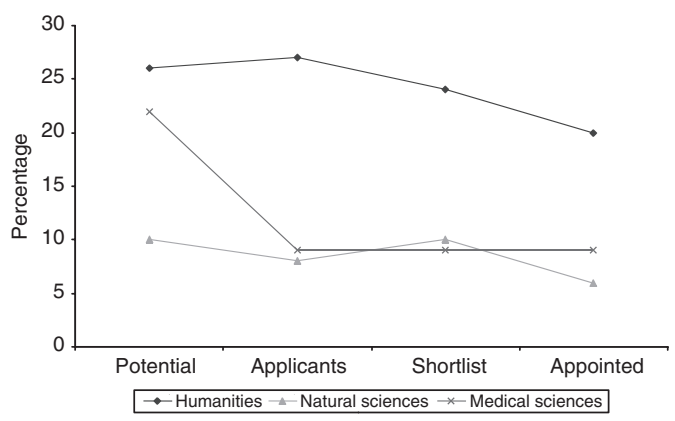

Figure 1: The proportion of women academics as potential, applicants (general and on the shortlist) and finally appointed, for each subfield

Source: Analysis appointment 565 reports (humanities $n=181$, natural sciences $n=191$, medical sciences $n=193)$. The difference between the total number of appointment reports analysed $(N=971)$ and the number of appointed reports in Figure 1 can be explained by the selection of three academic subfields for this article

identifying gender inequality makes us vulnerable to reading more inequality in the data than may exist. To prevent this, we have intentionally searched for deviant cases and alternative interpretations in all phases of the research.

The next section begins by reconstructing the leaky pipeline in the appointment process. Since the proportions of women in the pipeline differ between the fields of the medical sciences, natural sciences and humanities, we subsequently analyse the different gender inequality practices in these contexts to find how these intersect with gender equality policies.

\section{The leaky pipeline}

At every stage of the appointment process the number of women academics decreases and, as a result, the percentage of women full professors does not reflect the proportion of qualified women. In this section, we identify this leaky pipeline (Osborn et al., 2000; Pell, 1996; Rees, 2002) in each field by reconstructing the proportion of women in different stages in the appointment process. Figure 1 shows the proportion of women academics among the potential candidates, the applicants (in general and on the shortlist) and the professors appointed. ${ }^{1}$

The potential of women academics is the highest in the humanities $(26 \%)$ and increases further to 27 per cent among women applicants but declines towards the later stages of the selection process: and the proportion of women on the shortlist and in final appointments tails off. The pipeline leaks at the moment when selection begins and the proportion on women undergoes a more dramatic decline in the final selection. The situation in the natural sciences is rather different: the proportion of women applicants is slightly less than the potential of academic women, but the proportion of women on the shortlist rises slightly. The percentage of women finally appointed drops again. In the medical sciences, the proportion of women applicants and appointments is low $(9 \%)$ despite a large proportion of qualified women $(22 \%)$. The difference between the potential and expected women applicants is immediately obvious. Once invited to appear before the committee, the percentage of women on the shortlist and those finally appointed stays the same.

What these figures show, then, is that success rates of men and women vary considerably between academic fields but in all of them the success rate of women is lower than that of men. These differences on the leaky pipeline in science are corroborated by the US National Academy's Report 'Beyond Bias and Barriers' (National Science Foundation, 2007). The reduction in the biological 
sciences, with a larger pool of women academics is greater, as in the humanities, whereas the physical sciences are more similar to the field of natural sciences in this study. The patterns of the leaky pipeline in our data also differ, which brings us to the question of the specific gender practices in these fields that account for the lower success rate of women - each field's specific pipeline.

In the next section we describe the dominant gender inequality practices and analyse how they interact with gender equality practices in the three fields. The gender equality practices that will be reviewed are the prevailing measures that were referred to most frequently by interviewees when discussing current tools to undo the dominant inequality practices in that field. These were, respectively, the transparency of procedures and mentoring in medical sciences, the introduction of special women's chairs in humanities and the explicit search for women in the natural sciences. The quotes have been selected because they convey most powerfully the experience that was expressed by many respondents.

\section{Medical sciences: women as the 'other'}

\section{Gender inequality practices}

Nowhere is the leak in the pipeline more obvious than in the field of the medical sciences. While there is a substantial pool of qualified women (22\%), the percentage of women applicants drops towards 9 per cent. Although it is possible that more women opt for another career than men - which some respondents suggested - this argument does not hold because of the substantial share of women associate professors $(16 \%)$. A better explanation for the sudden decrease is the high number of closed recruitment $(77 \%)$ in the medical sciences. In closed recruitment procedures candidates are invited by scouts through formal and informal networks, which means that academics search in their own networks for eligible candidates and use their own view of excellence to assess these candidates. Our data illustrate that talented women are systematically overlooked due to the overrepresentation of men on scout positions and their homogeneous masculine networks in combination with the embedded notion that women are different or 'others', and therefore considered less suitable. We discern two salient gender inequality practices leading to a neglect and underestimation of talent women: (a) the paternalistic view of scouts and (b) the image that women do not correspond to the image of the ideal manager.

The first gender inequality practice is the paternalistic view of some respondents that the role of professor is too much to expect of a woman, so that women are not seen as obvious choices for professorships. They share the opinion that being a full professor is very hard for women because it is a demanding job and a vocation rather than an occupation. A male respondent illustrates this by arguing that a woman with care responsibilities has to convince the committee that work will take priority, while a man with family responsibilities is rarely asked about his plans to combine family with work. The following quote illustrates how this particular type of strategic communication and interpretation takes place:

It is possible that women are more often put on the defensive [during the selection interview] because they have a family with young children. It shouldn't be happening but the committee will wonder whether it can - or should - demand 100 or 150 per cent dedication of somebody with three children. You shouldn't be doing that as a committee, but if someone takes that into account without saying it, you will not find out. That is why as a woman, you should try not to be put on the defensive. If you have three children you have to make it clear to the committee how you think you are going to manage this. (Man, committee chair)

This quote also illustrates that a committee sometimes tries to be protective towards women and wonders whether they 'can ask this of a woman'. Other members argued that 'it is impossible to combine' (female committee member); 'can be hard in daily practice' (male committee chair) and 'you shouldn't place such high demands on women candidates with family responsibilities' (male 
committee member). Men committee members feel the need to 'protect' women from this heavy duty by not appointing them. So if committee members take a traditional view of care responsibilities, there is a reasonable chance that they will assume that a woman will have trouble managing her work. Martin (2006, p. 262) calls this 'paternalistic masculinity'. Although well-intended, it perpetuates the stereotypes upon which it is premised: women's role is to take care of the children. Care-taking responsibilities are seen as exclusively women's problems since these arguments are never discussed with male candidates. Men do not have to justify the arrangement of their family responsibilities. This means women have to counteract stereotypical images on the part of committees with traditional attitudes towards gender roles.

Secondly, our data show that women candidates are seen as different from men when judged alongside the stereotypical ideal of the strong, authoritarian, masculine leader. In medical sciences the high-risk factor means that an important talent for a full professor is the ability to manage the competitive and stressful combination of science and medical care. The interview material and the appointment reports showed that women's leadership skills were regularly questioned. Women made - so was said - too modest an impression and it was not believed they could survive in the tough, hierarchical medical field:

That woman, who was one of the final four candidates, had a great résumé, sufficient, more than sufficient publications with some experience of supervising $\mathrm{PhD}$ candidates, experience with contract research. She met most of the criteria. But she failed on academic leadership. I had my doubts about this and the other committee members did as well, including the women. We thought that she was too diffident, not vigorous enough, not capable of managing the group, to be the boss. I just thought she was too sweet. (Man, committee member)

Once I heard the story of a very competent candidate, a woman, small in size, fragile, and a [male] member of the university board said: 'Well, should we take that girl?' So physical appearance is something crucial. (Man committee member)

This last quote illustrates that the physical appearance of this candidate affected how the committee assessed her competence to be given a full professorship. Her petite feminine appearance influenced both their perceptions of her behaviour and the abilities they ascribed to her. The member of the university board cast doubt on her suitability by referring to her as 'girl', the implication being that a girl would certainly not survive in a competitive academic environment. Judgments are made about the management capacities of men and women on the basis of personal characteristics. Women are not seen as qualified because of the unusually high standards required. Men are treated as the reference point and women as the 'other' that deviates from this reference (Czarniawska and Höpfl, 2002; Eveline and Booth, 2004; Oppenheim Mason, 1986). Women tend to be seen as 'other' because their appearance fails to inspire predominantly male committee members with confidence that they have the kind of leadership skills needed in the medical sciences today.

\section{Gender equality practices versus gender inequality practices}

Gender equality practices in medical sciences mobilized to undo persistent gender inequality practices are protocols concerning an open recruitment process and coaching and mentoring of women faculty. Findings of gender research (Academy of Finland, 1998; Allen, 1988; Brouns and Addis, 2004; EU, 2008; Husu, 2000; Ledwith and Manfredi, 2000; Rees, 2004; van Balen, 2001) have led to calls for more transparent and open procedures and accountability among decision-makers in order to remedy the bias and arbitrariness of opaque appointment processes and guard against the reproduction of gender inequality practices that hamper the career progression of women. Universities and medical schools uphold the official standards concerning open recruitment; the open and public advertisement of vacancies so that all eligible candidates have the opportunity to apply. Our data have made it clear that the reality of practice deviates dramatically from the standards of open recruitment. More than three-quarters $(77 \%, n=211)$ of newly appointed professors were recruited by closed 
procedures. Due to a lack of commitment on the part of key individuals and a lack of pressure from the university board, the official policy of open and transparent recruitment remains a paper tiger. In the most extreme case, the policies to promote open recruitment have been countered, for example by committee members using techniques and strategies to appear to be transparent or to be following the gender equality regulations while manipulating the system in their interest behind the scenes.

We have found that the pressure from the board to open up these procedures and announce the vacancies publicly often leads to the mere semblance of transparency. The respondents, and also the appointment reports, reveal that the consequence of this pressure to make the vacancy public can lead to a veneer of transparency. Vacancies are advertised in the media, but in reality the preferred candidate is already known, the profile attuned to this candidate and other academics who might apply for the position are part of a purely decorative appointment procedure. Thus, the gender equality practice of promoting open recruitment has actually legitimized current methods of recruitment and selection practices by lending gender inequality practices a spurious objectivity. Due to the fact that these transparency and accountability policies exist on paper, the hegemonic discourse among committee members on fairness and meritocracy in the appointment process is strengthened still further. The norms of transparency, accountability and gender equality veil the practice of inequality; the norm is conceived as the practice and the fact that these policies are routinely ignored is hushed up (Van den Brink et al., 2010).

The gender equality practices of mentoring and coaching mainly pertain to the mobilization of (potential) women candidates and the development of leadership skills. These measures then, mainly adhere to gender equality from an equal opportunities perspective - helping women to adjust to the male world. The focus is on enlarging women's ambitions and making them visible as serious professorial candidates (Benschop, 2007). As important as these measures are, when implemented alone as the primary solution to the problem of gender inequality among full professors they have a limited effect on the structure, norms and practices in academia. They can even strengthen the idea that women are the problem and have to be fixed instead of the academic system itself.

\section{Humanities: a crowded house}

\section{Gender inequality practices}

Our data shows that this field has the largest proportion of women candidates (26\%), but this proportion decreases considerably during the appointment process $(20 \%)$. Characteristics of this field are fierce competition between academics due to a large number of educated professionals, abundant junior staff and a scarcity of top-level positions. The scarcity of positions is mainly caused by fewer national and international funding possibilities and limited career prospects for academics outside the university (Nederlandse Organisatie Voor Wetenschappelijk Onderzoek, 2007). For that reason, the stakes of appointments are high; both for the candidates and for the research group. Our interviewees referred to a relatively idiosyncratic and political context in which power struggles between fields, disciplines and epistemic cultures can come to the fore in the final decision-making. Connections with academic elites and knowledge of how things 'work around here' are crucial for success. Most of the respondents complain about the lack of transparency in the appointment system which, in their view, originates from the old academic tradition of this field where positions were assigned to a 'crown prince'.

The dominant gender practices that produce inequality in this field can be related to the exclusionary effect of masculine information and support systems. These patriarchal support systems (Bagilhole and Goode, 2001) have a strong exclusionary effect in terms of access to professorial positions and social networks that facilitate insight information about vacancies and job criteria. In order to increase their visibility, influential scientists can recommend candidates when names are asked for, encourage candidates to apply and help them make their name. It is essential that potential candidates are encouraged to apply or that the vacancy is explicitly pointed out by colleagues and superiors: 
My own promoter has always supported me when I asked him to. But he never supported my career on his own initiative, as far as I know, and nominated me for things. Never, never. It is not something he usually does, but I know he has done it for some men around him.... Actually, he has never understood that I have just as much ambition in this area as men have. And that is not because he isn't the sweetest man or doesn't care about me. That is not the case. But he doesn't realize that all this is as important for me as it is for my male colleagues. He once told me this honestly, that the penny hadn't dropped. (Woman, committee chair)

A more subtle way of exclusion is the uneven access to knowledge on the rules of the academic career game. 'In order to know how to play it, it is beneficial to have a mentor or contacts with the "old academic elite" ' (committee member). Because of the large influence of invisible connections and tacit rules and criteria it is hard for newcomers and outsiders to be a member of this inner circle. Women respondents argue they often lack access to these patriarchal support networks and are unaware of the tacit rules that are necessary to operate in this idiosyncratic environment. Unofficially required criteria can be difficult to identify for a candidate who does not know the existing arrangements. As a consequence, women are viewed as not operating strategically enough to survive in this highly idiosyncratic environment. Some male respondents illustrate this with such statements as 'women are not slick enough', 'don't know the rules of the game' and 'put all their cards on the table'. Academic male elites nurture their male successors from the beginning of their career and teach them the informal rules of the field, so that they know how to survive in this highly political culture:

Eventually, he will - well, I will not hold this position forever - have to be positioned as an excellent professor with experience in management, and so on. Therefore he will have to follow all these courses, and spend many hours on research. He has to have that [experience] by the time I leave in about 5 years ... so, we put those people [prospective successors] into position. (Man, committee chair)

As with the preferential treatment of men, masculine support networks offer advantages to academics who seek to raise their profile and build a reputation as an academic. Excellence is not something one is born with but is the outcome of a stimulating work environment, infrastructure and social capital that has to be given meaning and valued in a certain context. Due to the same homophily or masculine relationships men tend to help their own sex in an unintentional, matter-of-fact way. Women receive less reflexive help from these influential support systems.

\section{Gender inequality practices versus gender equality practices}

The dominant gender equality practices in the humanities mainly imply special chairs and mentoring programmes for women so that women do not have to compete with men or lose the competition due to strong gender stereotypes (Ridgeway and Smith-Lovin, 1999) and clone behaviour (Essed, 2004). Although special chairs give women the opportunity to be appointed in disciplines in which they are underrepresented, strong gender inequality practices withhold the intended effect. On the one hand, men and women interviewees indicate that specific support policies, such as women-only fellowships or professorial chairs, are needed to encourage women to stay in the academic community. On the other hand, both men and women argue against these policies due to the possible gender discrimination it induces.

Special women's programmes or chairs are not uninimously supported by most of the committee members interviewed. Our data also showed that some women were unhappy with how they were viewed after being awarded a grant for women only. An additional problem reported by women respondents was that, even if they would have been hired anyway and therefore would have received the funding through the regular channels, their male colleagues now directed them repeatedly to the special women's programmes. In this way women report becoming trapped in areas with women's funds. 
Resistance to the reservation or creation of chairs for women is mostly prompted by the strong ideology of meritocracy: one should be appointed on the basis of merit and not gender. This ideology is strongly present in all fields but it is most salient in the humanities because most respondents regard the gender issue as outdated in light of the relatively large share of women among academic staff members and students. The academic recruitment system is therefore assumed to be gender neutral and to offer equal opportunities to all candidates in so far as they are equally meritorious. Gender is not seen as something that matters in the selection of a full professor. Yet our data show that organizational practices continue to categorize men and women and masculinity and femininity hierarchically. This ideology renders invisible the discrepancy between academic values (merit) and actual practices and outcomes (the unequal share of women appointed) (Benschop and Doorewaard, 1998). Due to this process of hidden inequality the academic system goes unquestioned: standards for promotion and appointments are seen as gender neutral, offering the same chances to all candidates. In the eyes of most interviewees, gender inequality is therefore automatically related to women's personal choices. They argue that women lack the track record or experience to be appointed but this has nothing to do with the organization: the system itself is beyond reproach. The effectiveness of gender equality is mitigated by women that refuse to take positions that are installed for them, out of fear of being marked out as an 'affirmative action' case.

\section{Natural sciences: the ideal scientist}

\section{Gender inequality practices}

This field exhibited the smallest discrepancy between potential women candidates $(10 \%)$ and appointments $(6 \%)$, meaning that a large proportion of potential female candidates achieve their goal. However, the number of women ultimately appointed to professorial chairs is still not in line with the potential number. Women seem to lose the competition in the final stage (see Figure 1). One of the respondents suggested a possible explanation: the shortlisted women are underqualified, but are put on the shortlist regardless and lose the competition to better qualified men. The interviews reveal that women often lose the competition because of a lack of 'quality points'. Although committee members seem to have the best intentions, they argue that they are not willing to lower the standards of the required number of top publications or international experience. Women are welcome, but only when they conform to existing image of the ideal scientist (Acker, 1992), meaning a more than full-time devotion and willingness to spend long periods abroad. The masculine model of the ideal academic remains unquestioned. Women faculty members are expected to be able to follow this model with a little extra help, with mentoring and coaching. The assumption is that women who follow this model will be as successful as their male colleagues (Bailyn, 2003).

It is questionable whether women lose the competition because they lack quality points or because decision-makers perceive they lack this quality. Many studies have convincingly shown that women's qualities are systematically undervalued (Cole et al., 2004; Foschi, 1996; Wennerås and Wold, 1997). Women in a token position are visible but also have to deal with prejudice and stereotypes (Kanter, 1977). Kanter suggests that the sex ratio of a group determines their perceptions of behaviour and the position of tokens within the group. While members of the majority are regarded as individuals, tokens symbolize the minority they belong to and are considered representative of that minority. The 'intrinsic' ability of women to excel in natural and technical sciences is often questioned (Fox Keller, 1985; Schiebinger, 1989). In the context of the final selection, this might mean that committee members' perceptions and evaluations of competence and performance are also skewed to the point that women are consistently underrated and men consistently overrated.

Masculinity and power are intertwined in such a way that men represent the standard; they naturally represent the norm against which the performance of women is measured. In other words, the attributes stereotypically labelled as masculine - such as technical ability, psychical strength and being goal-oriented - are valued more highly and taken to be the natural norm. Women in this 
masculine field may experience increased pressure to perform in order to counter stereotypical images. A more profound approach that scrutinizes and challenges the masculine notion of the ideal scientist is needed.

\section{Gender equality practices versus gender inequality practices}

In the natural sciences we experienced a willingness to support talented women, leading to gender equality practices such as searching explicitly for women candidates and putting in extra effort when a woman applicant is eligible. Adding more women was perceived by committee members as the only way to break the circle of not having examples to emulate (role models) and to help to remedy the unfashionable image of the natural sciences. In line with the policies of gender equality, although this was not included in formal policies, a stronger desire to appoint more women in senior positions was detected, particularly in those fields where women are underrepresented. In general, respondents appreciated the urgency of appointing more women on senior positions: 'Women have a different leadership style, which we really need here'; 'They have to serve as role models for our women students' (male dean); 'we need to attract more women students into physics and chemistry' (male committee member) but also: 'It could change the atmosphere in a positive way' (male committee chair) and even: 'It would be more natural' (male committee member). Many committee members are convinced that women add to science and have a special contribution to make.

Special attention has been given to searching for female candidates to appoint them as full professors to these committees and this demonstrates that the issue is indeed on the agenda of committee members. However, such gender equality practices appear to be more like sticking plaster than a permanent solution. The issue that hinders gender equality practices from being effective is the inevitable quality discussion. Women benefit from this special search for women as they make it to the short list relatively often. In the final appointment however, the difference arguments that women add to science do not hold, as the norms of the ideal scientist prevail in the final selection. While many committee members are convinced of the need to prioritize the search for women, later in the same interviews they also vent their concerns about the quality of the candidates: 'We are not interested in gender, only in appointing the best qualified candidates' (male dean). Controversy surrounds the search for women candidates as this method could mean that less qualified women are hired. Our analysis of the appointment reports shows that the quality argument is hardly ever mentioned in relation to the appointment of men candidates.

Gender equality policies based on difference do not match well with a construction of quality based on a meritocratic norm. The overall norm of the natural scientist remains intact and as masculine as ever and both women and men are held against that norm. The different qualities that women allegedly bring pertain to people skills and those play a subordinate part to the masculine norm of the ideal scientist. The gender equality practices in the natural sciences help to bring potential women candidates to the attention of selection committees. These attempts are mitigated by stronger gender inequality practices that mean that women do not make it to the final selection.

\section{Discussion and conclusion}

In this article we have offered insights on normally impermeable academic practices that stay largely undocumented due to privacy issues. We have shown that gender is not a static entity but a dynamically situated social practice that operates in various structural and cultural academic contexts. Without wanting to imply that some gender inequality practices occur only in certain fields we have observed that different gender inequality practices were most salient in each context. The exclusionary effect of informal recruitment by scouts mean that women candidates are not invited to apply for professorships in the medical sciences. In the humanities, the exclusionary effect of masculine information and support systems affects women candidates in all phases of the appointment process. 
And finally, in the natural sciences women lose the competition in the final selection as their qualities are questioned and measured against a masculine standard.

To understand the slow pace of change, we have analysed how gender inequality practices interact with gender equality practices. We offer three explanations for the slow change. Firstly, analysis of the current gender equality policies shows that many interventions for achieving gender equality in organizations target women candidates. These interventions often derive from liberal feminist theories, which focus on the barriers women encounter in organizations and focus on women as their solution (Ely and Meyerson, 2000; Liff and Cameron, 2002), such as mentoring and providing special women's chairs. Although these interventions often result in significant and necessary changes in organizations they are 'not sufficient to disrupt the pervasive and deeply entrenched imbalance of power in the social relations between men and women' (Ely and Meyerson, 2000, p. 589). Structural change within the organizations themselves is not attempted. If we really want to bring about change, the system itself must change and gender must be practiced differently. In other words, gender inequality practices need to be undone. Academics ought therefore to reflect on why these gender imbalances persist in higher positions, how they come about and who benefits from keeping them in place. More structural action should include interventions that change 'the way we do things here'. This calls for reflection on the current gender inequality practices in recruitment and selection and explicit attempts to break fossilized patterns. Gender awareness training of committee members, for instance, such as that developed by the University of Michigan, ${ }^{2}$ could be a first step in this reflection. Yet gender awareness training is effective only when it is implemented in actual appointment practices. More attention should thus go to the incorporation of gender awareness into the messy realities of actual professorial appointments.

Secondly, future policies should take into account gender dynamics in the various fields. University-level policies designed to address the underrepresentation of women academics tend to generalize all academic fields. Our study demonstrates that academic fields are gendered somewhat differently and that tackling the underrepresentation of women requires a variety of gender equality measures tailored to the specific discipline or field. In the medical sciences much is to be gained from a more diverse group of scouts with ties to varied networks, and from a more open way of recruitment. Furthermore, recruiters in the medical sciences should be made aware that female talent is available and women (including mothers) can harbour the same ambitions of becoming full professors as their male counterparts. They should not be overlooked simply because existing senior academics hold the paternalistic view that combining a career with family responsibilities is too hard for women. For the humanities, more structural change could come from strategic alliances between women candidates and men in decision-making positions. Mentors are often proposed as being helpful for women, yet the mentors themselves have a lot to learn about the inclusion and support of female talent. Recruiters in the humanities need to become aware that gender inequality needs to be undone and that this requires interventions that go beyond special chairs and target regular procedures. In the natural sciences, it takes reflection on the mismatch between women candidates and the dominant image of the ideal scientist. The tendency to systematically underrate women in competition with men is difficult to counter. The inclusion of female committee members has proved to be an effective measure to get more women appointed (NSF, 2009; Van den Brink, 2010). Moreover, assessors should look beyond the normal way of evaluating the quality of the candidates. Norms on productivity often emphasize the research output of a candidate but should be correcting for the input. Academics with alternative career paths or career interludes often lose out even when they are gifted scientists (Stobbe et al., 2004; Valian, 1998). While these gender equality practices have the potential to undo inequality, we should reckon with counter effects.

These counter effects constitute the third and final reason why change is so slow. Our research has shown that equality practices are intertwined with a myriad of gender inequality practices. These gender inequality practices cover up, change the direction of, or even hijack gender equality practices. This has been shown by the inequality practices that hinder, alter or transform equality measures. For example, the establishment of special chairs for women mitigates the dominant inequality practice of support of men by male scouts. Simultaneously, these gender equality 
practices lead to questions about the woman appointee's quality, which is suspect when not tested in competition with men or measured against male competitors. As a result, some women academics refuse to take positions that are established for women, out of fear of being marked out as an 'affirmative action' case. The transparency policies make for a second example. These policies are designed to counter gender inequality by advocating open recruitment so that recruitment bias is limited and a wide variety of applicants can be addressed. The norms of transparency and open procedures veil the practice of gender inequality when designated candidates are singled out in closed procedures, while people adhere to the rules that prescribe open competition between candidates. Gender equality practices thus unintentionally silence debate on favouritism rather than achieving actual transparency. A third example pertains to the equality practice of explicitly searching for women candidates because they would add to science and have a special contribution to make. This leads to a substantial increase of women on the long list. Our data have shown that in the end, the gender equality practices are hijacked by the persistent inequality practices of questioning women's qualities and constructing those qualities as inferior to men's (Van den Brink et al., 2011).

This article has contributed to our knowledge on why gender change in academia is so awfully slow and why it is so hard to undo gender inequality in daily practice. In our opinion, undoing gender simultaneously implies doing gender and it would be more fruitful to distinguish between multiple inequality and equality practices if we are to disrupt gender inequalities and bring about sustainable gender change. In our research, the gender equality practices were unable to counter the multitude of gender inequality practices; their sword was too blunt, there are simply too many heads on the dragon and each requires a specific attack. This explains why it is often so difficult to undo inequality; simultaneous multi-faced gender inequality practices are ineffectively countered by gender equality practices because those lack teeth, especially in traditional masculine academic environments with 'thick', ponderous traditions and values. We conclude that there is no one-sizefits-all approach that can undo inequalities. Clearly, research on effective measures and interventions should continue to come up with sharper swords to slay the dragon.

\section{Notes}

1. For the purposes of this study, the available female pool of talent for full professors is defined using two criteria: (a) the proportion of female doctorate holders (1986-1992) and (b) the proportion of female associate professors (1999-2005). A candidate is someone who has applied for a position or who has been nominated by related faculties or a member of the appointment committee and who has notified the committee that he or she is interested in the position. Shortlisted candidates have passed the first stage of selection and committee members regarded them as serious candidates for the professorial position.

2. The Advance project at the University of Michigan developed 'strategies and tactics for recruiting to improve diversity and excellence' for members of selection committees. More information is accessible through the ADVANCE web portal (n.d.).

\section{References}

Academy of Finland (1998) Women in Academia. Report of the Working Group Appointed by the Academy of Finland. Helsinki: Academy of Finland.

Acker, J. (1990) Hierarchies, jobs, bodies: a theory of gendered organizations, Gender and Society, 4,2, 19.

Acker, J. (1992) Gendering organizational theory. In Mills, A.J. and Tancred, P. (eds) Gendering Organizational Analysis, pp. 248-60. London: Sage.

ADVANCE (n.d.) Home page available at http://www.portal.advance.vt.edu/. Last accessed 11 May 2011

Allen, N. (1988) Aspects of promotion procedures in Australian universities. Higher Education, 17, 267-80.

Alvesson, M. and Billing, Y. (2009) Understanding Gender and Organizations. London: Sage.

Bagilhole, B. and Goode, J. (2001) The contradiction of the myth of individual merit, and the reality of a patriarchal support system in academic careers; a feminist investigation. The European Journal of Women's Studies, 8,2, 161-80. 
Bailyn, L. (2003) Academic careers and gender equity: lessons learned from MIT. Gender, Work E Organization, 10,2, 137-53.

Balen, B. van (2001) Vrouwen in de wetenschappelijke arena. Sociale sluiting in de universiteit. Amsterdam: Het Spinhuis.

Becher, T. and Trowler, P. (2001) Academic Tribes and Territories. Intellectual Enquiry and the Culture of Disciplines. Buckingham: Open University Press.

Benschop, Y. (2001) Gender and organizations. In International Encyclopedia of Business and Management. $2^{\text {nd }}$ edn. Pp. 2262-9. London: Thomson.

Benschop, Y. (2007) Van lippendienst tot tegengas. Een kritische benadering van gender in organisatieverandering. Inaugural address by Professor Yvonne Benschop [From lip service to resistance. A critical approach of gender in organizations]. Nijmegen: Radboud University Nijmegen.

Benschop, Y. and Doorewaard, H. (1998) Covered by equality: the gender subtext of organizations. Organization Studies, 19,5, 787-805.

Bourdieu, P. (1988) Homo Academicus. Cambridge: Polity Press.

Brouns, M. and Addis, E. (2004) Synthesis report on the workshop. In Brouuns, M (ed.) Gender and Excellence in the Making, pp. 13-32. Brussels: European Commission.

Butler, J. (2004) Undoing Gender. New York: Routledge.

Cole, M., Field, H. and Giles, W. (2004) Interaction of recruiter and applicant gender in resume evaluation: a field study. Sex Roles, 51,9-10, 597-608.

Cownie, F. (1998) Women legal academics: a new research agenda? Journal of Law and Society, 25,1, 102-15.

Czarniawska, B. and Höpfl, H. (eds) (2002) Casting the Other: the Production and Maintenance of Inequalities in Work Organizations. London and New York: Routledge.

Deutsch, F.M. (2007) Undoing gender. Gender and Society, 21,1, 106-27.

Ely, R.J. and Meyerson, D.E. (2000) Advancing gender equity in organizations: the challenge and importance of maintaining a gender narrative. Organization, 7,4, 589-608.

Essed, P. (2004) Cloning amongst professors: normativities and imagined homogeneities. NORA, 12,2, 113-22.

EU (2008) Mapping the Maze. Getting More Women to the Top in Research. Brussels: European Commission.

EU (2009) She Figures. Women and Science, Statistics and Indicators. Brussels: European Commission.

Eveline, J. (2005) Woman in the ivory tower. Journal of Organizational Change Management, 18,6, 641-58.

Eveline, J. and Booth, M. (2004) 'Don't write about it': writing 'the other' for the ivory basement. Journal of Organizational Change Management, 17,3, 243-55.

Foschi, M. (1996) Double standards in the evaluation of men and women. Social Psychology Quarterly, 59,3, 237-54

Fox Keller, E. (1985) Reflections on Gender and Science. New Haven, CT: Yale University Press.

Gerritsen, M., Verdonk, T. and Visser, A. (2009) Monitor Vrouwelijke Hoogleraren. available at http:// test16.hosting.rug.nl/index.php/component/content/article/1-nieuwe-monitor-vrouwelijke-hoogleraren2009 Last accessed 12 July 2009.

Gherardi, S. (1994) The gender we think, the gender we do in our everyday organizational lives. Human Relations, $47,6,591-610$.

Husu, L. (2000) Gender discrimination in the promised land of gender equality. Higher Education in Europe, 25,2, 221-8.

Kanter, R.M. (1977) Men and Women of the Corporation. New York: Basic Books.

Kekäle, J. (1999) Preferred patterns of academic leadership in different disciplinary (sub)cultures. Higher Education, 37,3, 217-38.

Kelan, E.K. (2009) Gender logic and (un)doing gender at work. Gender, Work E Organization, 17,2, 174-94.

Kirton, G. and Greene, S.G. (eds) (2005) The Dynamics of Managing Diversity. Oxford: Elsevier and ButterworthHeinneman.

Knights, D. and Richards, W. (2003) Sex discrimination in UK academia. Gender, Work \& Organization, 10,2, $213-38$.

Knorr Cetina, K. (1999) Epistemic Cultures; How the Sciences Make Knowledge. Cambridge MA: Harvard University Press.

Krefting, L.A. (2003) Intertwined discourses of merit and gender: evidence from academic employment in the USA. Gender, Work \& Organization, 10,2, 260-78.

Ledwith, S. and Manfredi, S. (2000) Balancing gender in higher education. The European Journal of Women's Studies, 7,1,7-33.

Lieblich, A., Tuval-Mashiach, R. and Zilber, T. (1998) Narrative Research: Reading, Analysis and Interpretation. Thousand Oaks, CA and London: Sage.

Liff, S. and Cameron, I. (2002) Changing equality cultures to move beyond 'women's problems'. Gender, Work E Organization, 4,1, 35-46.

Lorber, J. (2005) Gender Inequality, Feminist Theories and Politics. Los Angeles: Roxbury Publishing Company.

Martin, P.Y. (2006) Practising gender at work: further thoughts on reflexivity. Gender, Work E Organization, 13,3, 254-76.

Maton, K. (2005) A question of autonomy: Bourdieu's field approach and higher education policy. Journal of Educational Policy, 20,6, 687-704.

Musselin, C. (2002) Diversity around the profile of the 'good' candidate within French and German universities. Tertiary Education and Management, 8,3, 243-58. 
National Science Foundation (2007) Beyond Bias and Barriers. Fulfilling and Potential of Women in Academic Science and Engineering. Washington: NAP.

Nederlandse Organisatie Voor Wetenschappelijk Onderzoek (2007) NWO in cijfers (NWO in figures) available at http://www.nwo.nl/nwohome.nsf/pages/NWOP_6EYCLQ Last accessed 12 September, 2007.

Ollerenshaw, J.A. and Creswell, J.W. (2002) Narrative research: a comparison of two restorying data analysis approaches. Qualitative Inquiry, 8,3, 329-47.

Oppenheim Mason, K. (1986) The status of women: conceptual and methodological issues in demographic studies. Sociological Forum, 1,2, 284-300.

Osborn, M., Rees, T., Bosch, M., Hermann, C., Hilden, J., Mason, J., et al. (2000) Science Policies in the European Union: Promoting Excellence through Mainstreaming Gender Equality. Brussels: European Commission.

Pell, A.N. (1996) Fixing the leaky pipeline: women scientists in academia. Journal of Animal Science, 74,11, 2843-8.

Poggio, B. (2006) Editorial: outline of a theory of gender practices. Gender, Work E Organization, 13,3, 225-33.

Pullen, A. and Knights, D. (2007) Undoing gender: organizing and disorganizing performance. Gender Work $\mathcal{E}$ Organization, 14,6, 505-11.

Rees, T. (2002) The Helsinki Group on Women and Science: National Policies on Women and Science in Europe. Brussels: European Commission.

Rees, T. (2004) Measuring excellence in scientific research: the UK research assessment exercise. In Brouns, M. (ed.) Gender and Excellence in the Making, pp. 117-23. Brussels: European Commission.

Ridgeway, C.L. and Smith-Lovin, L. (1999) The gender system and interaction. Annual Review of Sociology, 25, 191-216.

Schiebinger, L. (1989) The Mind Has No Sex? Women in the Origins of Modern Science. Cambridge, MA: Harvard University Press.

Stobbe, L. Van den Brink, M. and Duijnhoven, S. (2004) Images of Science, Scientific Practice and Femininity Amongst Physicists. Utrecht: FOM.

Tienari, J., Quack, S. and Theobald, H. (2002) Organizational reforms, 'ideal workers' and gender orders: a cross-societal comparison. Organization Studies, 23,2, 249-79.

Valian, V. (1998) Why So Slow: the Advancement of Women. Cambridge, MA: MIT Press.

Van den Brink, Marieke (2010) Behind the Scenes of Science: Gender Practices in Recruitment and Selection of Professors in The Netherlands. Amsterdam: Pallas.

Van den Brink, M. and Stobbe, L. (2009) Doing gender in academic education: the paradox of visibility. Gender, Work E Organization, 16,4, 451-70.

Van den Brink, Marieke, Benschop, Yvonne and Jansen, Willy (2010) Transparency as a tool for gender equality. Organization Studies, 31,11, 1459-83.

Walby, S. (2005) Gender mainstreaming: productive tensions in theory and practice. Social Politics, 12,3, $321-43$.

Wennerås, C. and Wold, A. (1997) Nepotism and sexism in peer-review. Nature, 387, 341-43.

West, C. and Zimmerman, D. (1987) Doing gender. Gender and Society, 1,2, 125-51.

Yanow, D. (2006) Talking about practices: on Julian Orr's talking about machines. Organization Studies, 27,12, $1743-56$. 
JOBNAME: No Job Name PAGE: 16 SESS: 8 OUTPUT: Fri May 27 17:54:22 2011 SUM: 233D9984

\begin{tabular}{|l|l|}
\hline \multicolumn{2}{|c|}{ Toppan Best-set Premedia Limited } \\
\hline Journal Code: GWAO & Proofreader: Elsie \\
\hline Article No: 566 & Delivery date: 27 May 2011 \\
\hline Page Extent: 15 & \\
\hline
\end{tabular}

\section{AUTHOR QUERY FORM}

Dear Author,

During the preparation of your manuscript for publication, the questions listed below have arisen. Please attend to these matters and return this form with your proof.

Many thanks for your assistance.

\begin{tabular}{|l|l|l|}
\hline \multicolumn{1}{|c|}{$\begin{array}{c}\text { Query } \\
\text { References }\end{array}$} & \multicolumn{1}{c|}{ Query } & Remark \\
\hline q1 & $\begin{array}{l}\text { AUTHOR: date changed throughout to match } \\
\text { reference list: please check }\end{array}$ & \\
\hline q2 & $\begin{array}{l}\text { AUTHOR: To match the reference list, should } \\
\text { NSF, 2009 be changed to National Science } \\
\text { Foundation, 2007? Please advise, }\end{array}$ & \\
\hline q3 & $\begin{array}{l}\text { AUTHOR: Van den Brink et al., 2011 has not } \\
\text { been included in the Reference List, please supply } \\
\text { full publication details. }\end{array}$ & \\
\hline q4 & $\begin{array}{l}\text { AUTHOR: Table 1 has not been mentioned in the } \\
\text { text. Please cite the table in the relevant place in } \\
\text { the text. }\end{array}$ & $\begin{array}{l}\text { AUTHOR: Please provide the running head } \\
\text { details. }\end{array}$ \\
\hline q5 & & \\
\hline
\end{tabular}


When you open your PDF file you should see the Comment \& Markup toolbar* listing from the left, the Sticky Note, Text Edits, Stamp and Highlighter tools, like this:

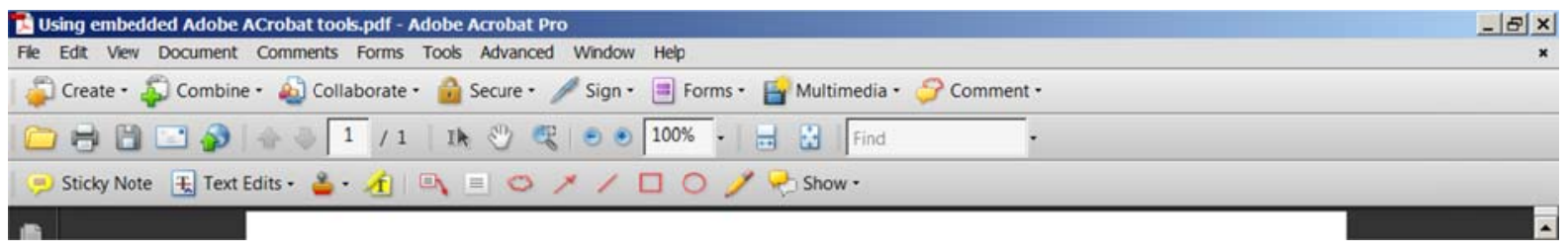

Sticky note

Use this to make comments and give instructions. Click on the tool (think of this as putting paint onto a paint brush), then click on the place in the document where you want make a comment. Type in your instruction into the yellow bubble that appears.

Text edits (use these to make corrections in the text)

To insert text: click on the text edit tool, insert the cursor at the point where you want to make an alteration and start typing.

To replace text: click on the text edit tool, insert the cursor in the text at the point where you want to make an replacement and select the text (the selection will be highlighted in blue). Start typing the replacement text (you do not need to delete anything).

To delete text: text: click on the text edit tool, insert the cursor at the point where you want to make a deletion, select text to delete and press 'delete' on the keyboard.

Stamp: there is no need to use this tool.

Highlighter

Use this to make a specific instruction (e.g. to change a phrase to italics). Click on the yellow pencil then select the text to be highlighted. Right click on the tool to open the highlighter box and type in you text, e.g. '<remove italics>'.

These are the only tools you need to use to mark up your document. It is best to give an instruction only once to make your corrections easy to read and understand (don't duplicate the sticky note and the text editing tool, for example).

Changing your edits: click on the edited text and change as required.

Deleting your edits: right click on the blue caret or blue or red crossed-out line, bubble or highlighted text and press 'delete' on the keyboard.

Reviewing your edits: click open 'Show comments list' in the Comments toolbar. Every correction you have made will be listed in the bottom pane that opens (to close, it click the right hand arrow at the top of the Comments pane).

* If you do not see the Comment \& Markup toolbar, click on Tools, click on Comment \& Markup then at the bottom of the menu, click on 'Show Comment \& Markup toolbar'.

\section{EXAMPLES}

\begin{tabular}{|c|c|c|}
\hline Sticky note & A bubble that you can click on to open & $\equiv$ \\
\hline Insertion & A blue caret at the point of insertion & it really is time we asked where we are going. \\
\hline Replacement & $\begin{array}{l}\text { A blue caret and blue line crossing out } \\
\text { the text }\end{array}$ & it really ig time we asked where we are going. \\
\hline Deletion & A red line crossing out the text & it really is time we asked where we are going. \\
\hline $\begin{array}{l}\text { Highlighted } \\
\text { text }\end{array}$ & Text is highlighted in yellow & is time we asked where we are going. \\
\hline
\end{tabular}

